\title{
Temperature history and accumulation timing for the snowpack at GISP2, central Greenland
}

\author{
C. A. Shuman, ${ }^{1}$ R. B. Alley, ${ }^{2}$ M. A. Fahnestock, ${ }^{3}$ R. A. Bindsghadler, ${ }^{4}$ J.W. C. White, ${ }^{5}$ \\ J. Winterle, ${ }^{6}$ J. R. MaConnell ${ }^{6}$ \\ ${ }^{1}$ USRA Visiting Research Fellow, NASA/Goddard Space Flight Center, Mail Code 971, Greenbelt, Maryland 20771, U.S.A. \\ ${ }^{2}$ Earth System Science Center and Department of Geosciences, The Pennsylvania State University, University Park, Pennsylvania 16802, U.S.A. \\ ${ }^{3}$ foint Center for Earth System Science, Department of Meteorology, University of Maryland, College Park, Maryland 20740, U.S.A. \\ ${ }^{4}$ Oceans and Ice Branch, NASA/Goddard Space Flight Center, Mail Code 971, Greenbelt, Maryland 20771, U.S.A. \\ ${ }^{5}$ Institute for Arctic and Alpine Research and Department of Geological Sciences, University of Colorado, Boulder, Colorado 80309, U.S.A. \\ ${ }^{6}$ Department of Hydrology and Water Resources, University of Arizona, Tucson, Arizona 85721, U.S.A.
}

\begin{abstract}
Previous research has documented a close association between highresolution snow-pit profiles of hydrogen and oxygen stable-isotope ratios and multi-year Special Sensor Microwave/Imager (SSM/I) $37 \mathrm{GHz}$ brightness temperature data in central Greenland. Comparison of the SSM/I data to profiles obtained during the 198991 field seasons indicated that $\delta \mathrm{D}$ and $\delta^{18} \mathrm{O}$ data from the near-surface snow at the Greenland summit are a reliable, high-resolution temperature proxy. To test this new technique further, additional stable-isotope data were obtained from a $2 \mathrm{~m}$ snow pit constructed during late-June 1995 near the GISP2 site.

This new profile, supported by pit stratigraphy and chemistry data, confirms the utility of comparing stable-isotope records with SSM/I brightness temperatures. The sub-annual variation of the $\delta \mathrm{D}$ record at the GISP2 site was determined using 15 match points, from approximately December 1991 through June 1995 and was guided in part by time-constrained hoar layers. The close association of these temperature proxies supports the assertion that snow accumulation occurs frequently through the year and that the isotope record initially contains temperature information from many times of the year. This is also independently confirmed by analysis of $\mathrm{H}_{2} \mathrm{O}_{2}$ data. The slope of the multi-year $T$ vs $\delta$ correlation was evaluated along with the sub-annual variation in the amount, rate and timing of accumulation. These new results are consistent with those from the previous study and they also demonstrate that the snow in this area initially contains temperature and chemical records with sub-annual resolution. This encourages confident interpretation of the paleoclimatic signal variations in the GISP2 and GRIP deep cores.
\end{abstract}

\section{INTRODUCTION}

As one part of an extensive re-analysis of stable-isotope thermometry conducted in support of the GISP2 and GRIP deep cores, Shuman and others (1995b) investigated the similarity of stable-isotope ratio $\left(\delta^{18} \mathrm{O}\right.$ and $\left.\delta \mathrm{D}\right)$ data from snow-pit profiles to multi-year satellite-brightness temperatures. That analysis found a close correspondence between stable-isotope profiles from three shallow snow pits and a multi-year daily brightness temperature record from the Scanning Multichannel Microwave Radiometer (SMMR) and Special Sensor Microwave/Imager (SSM/I) for the GISP2 site. A distinctive, multi-peaked temperature cycle observed with the longer-term satellite temperatures, and confirmed with shorter-term automatic weather station (AWS) data, appeared to be substantially preserved in the $\delta^{18} \mathrm{O}$ and $\delta \mathrm{D}$ records. The similarity between the trends, despite some anomalous events and the effects of progressive diffusion, supported the assertion that accumulation occurs at many times throughout the year and that isotopic profiles from central Greenland initially contain a temperature history with sub-seasonal resolution. In that paper, we concluded that additional comparisons using this technique should be made to assess the reliability of the technique. This paper provides additional data and analyses that support the earlier work and the trend-comparison technique.

\section{BACKGROUND}

From the days of the German and French studies in central Greenland at Stations Eismitte and Centrale, during the first half of this century, field scientists have struggled to monitor and understand meteorological conditions on the ice sheet (e.g. see Sorge, 1935). Later in this century, stable oxygen and hydrogen isotope-ratio data from polar icesheet sites have been used as a temperature proxy in support of climate interpretation and reconstruction (Benson, 1962; Dansgaard, 1964; Dansgaard and others, 1973; Hammer and others, 1978). Although the details of isotopic source, transport, delivery and preservation are complex (Epstein and Sharp, 1965; Johnsen, 1977; Kato, 1978; Fisher and others, 1983; Jouzel and Merlivat, 1984; Peel and others, 1988; Johnsen and others, 1989; Petit and others, 1991; Charles and others, 1994; Newell and Zhu, 1994), it is clear that long-term records of $\delta^{18} \mathrm{O}$ and $\delta \mathrm{D}$ from deep ice cores provide dramatic evidence of past climate change (Johnsen, 1977; 
Hammer and others, 1978; Dansgaard and others, 1985; Johnsen and others, 1989; Grootes and others, 1993; Cuffey and others, 1994; Cuffey and Clow, 1997; Jouzel and others, 1997). The persistent uncertainty regarding accumulation timing and preservation, moisture sources and vapor transport, and the initial isotopic content of snow and its subsequent diffusion in ice have until recently (Barlow and others, 1993; McConnell and others, 1997) limited detailed interpretation of high-resolution isotope profiles. Some of these issues are addressed here; others have been discussed by Cuffey and Clow, (1997), Grootes and Stuiver (1997) and Jouzel and others (1997) in the GISP2-GRIP Compendium Volume.

This study compares a high-resolution stable-isotope profile ( $2 \mathrm{~cm}$ incremental samples or about 25-35 samples per year) and multi-year, passive-microwave brightnesstemperature records calibrated by short-term AWS data. The empirical correlation or trend-comparison technique documented by Shuman and others (1995b) for the snowpit and satellite records has allowed (1) the sub-annual variation of the initial isotopic record at GISP2 to be temporally constrained, (2) identification of "anomalous" isotopic events and their impact on the records to be estimated, (3) evaluation of the slope of the $T$ vs $\delta$ correlation, (4) measurement of the amount, rate and timing of accumulation, and (5) a confirmatory analysis of the atmospheric $\mathrm{H}_{2} \mathrm{O}_{2}$ cycle in the GISP2 area. This should encourage application of this technique at other ice-sheet locations where satellite observations can provide a proxy temperature record for detailed comparison with stable-isotope and chemical records.

\section{METHODOLOGY}

As in the previous study, the passive-microwave data used here were extracted from U.S. National Snow and Ice Data Center CD-ROMs (NSIDC, 1992). Daily-averaged, $37 \mathrm{GHz}$, vertical polarization $(\mathrm{V})$, brightness temperatures $\left(T_{\mathrm{B}}\right)$ from the Special Sensor Microwave/Imager (SSM/I-F11) for the $25 \mathrm{~km} \times 25 \mathrm{~km}$ gridcell covering the GISP2 site were compiled to document the multi-year "temperature" trend for the site. Brightness-temperature data from the $37 \mathrm{GHzV}$ ( $0.81 \mathrm{~cm}$ wavelength) channel began in December 1991 and extend through September 1995. The measurement accuracy of the SSM/I channels is $\pm 2 \mathrm{~K}$ (Hollinger and others, 1990).

The relationship of brightness temperature to physical temperature is described by the Rayleigh-Jeans approximation (Hall and Martinec, 1985). Satellite brightness temperature $\left(T_{\mathrm{B}}\right)$ is primarily a function of the physical temperature of the near-surface snow $(T)$ multiplied by its emissivity $(\epsilon)$ (or $T_{\mathrm{b}} \sim T \times \epsilon$ ). Atmospheric effects on brightness temperature are ignored due to the low temperatures and limited water-vapor content found in this area (Maslanik and others, 1989). Other research indicates that emissivity is controlled primarily by radiative scattering from the ice grains over a skin depth of $1 \mathrm{~m}$ or so for the $37 \mathrm{GHz}$ channels but is dominated by the top $20-30 \mathrm{~cm}$ (Rott and others, 1993). This depth is equivalent to that of the diurnal temperature cycle (Alley and others, 1990). Overall, the emissivity of the snow and ice is controlled primarily by grain-size (Chang and others, 1976; Armstrong and others, 1993) which tends to vary over an annual period (Benson, 1962).
The $37 \mathrm{GHzV} T_{\mathrm{B}}$ data can be related to near-surface automatic weather station (AWS) air temperatures by a technique described by Shuman and others (1995a). In that paper, the short-term AWS temperature $\left(T_{\mathrm{A}}\right)$ and temporally equivalent $T_{\mathrm{B}}$ data are used to generate an approximate emissivity time series. From these data, a sinusoid is then fitted to the data which defines a modeled emissivity cycle. The modeled emissivity cycle can then be used to convert the $T_{\mathrm{B}}$ data into an estimated near-surface air temperature $\left(T_{\mathrm{C}}\right)$ with reasonable accuracy. The $37 \mathrm{GHzV}$ data are used for this technique, because they provide the best correlation of the available long-term passive-microwave channels with the mean daily air-temperature data from the AWS (Shuman and others, 1995a). Some difficulties in the utilization of this technique that were not addressed in the earlier work or in Shuman and others (1995b) will be discussed here.

A high-resolution isotope record was obtained during late-June 1995 from a snow pit located about $1 \mathrm{~km}$ west of the GISP2 site $\left(72^{\circ} 35^{\prime} 34^{\prime \prime} \mathrm{N}\right.$ and $\left.38^{\circ} 28^{\prime} 45^{\prime \prime} \mathrm{W}\right)$. The pit study included high-resolution sampling for stable hydrogen isotopes and back-lit pit-wall photography (see Fig. 1), a pitwall map of snow stratigraphy and a coincident snow-density profile. The pit was dug in a "clean" area to a depth of $2 \mathrm{~m}$ and was sampled at $2 \mathrm{~cm}$ resolution using standard field procedures for isotopes. The samples were analyzed at the Institute for Arctic and Alpine Research isotope laboratory (University of Colorado, Boulder) with uncertainties of \pm 0.5 per mil (\%o) for $\delta \mathrm{D}$. The results were reported in per mil relative to Standard Mean Ocean Water (SMOW).

As in the previous study, this paper is based on comparisons made using a qualitative, point-pairing procedure between the microwave brightness-temperature records and the $\delta \mathrm{D}$ profile that is guided by the shapes of the trends and in some cases by temporally constrained hoar layers (see Fig. 1; Table 1). Fundamentally, this involves examining temporally similar parts of the two records and making the assumption that the major peaks and/or valleys represent equivalent events in both records. It is worth pointing out that this technique would be difficult to apply in areas of extremely low or strongly seasonal accumulation. The resulting paired data (depth and associated $\delta \mathrm{D}$ value from the

Table 1. Descriptions of hoar layers observed in the 1995 pit stratigraphy

$\begin{array}{cccc}\text { Identifier * Depth } & \begin{array}{c}\text { Thick- } \\ \text { ness }\end{array} & \begin{array}{c}\text { Date }(s)^{\dagger} 1995 \\ (\text { day } / \text { month })\end{array} & \text { Observations } \\ \mathrm{cm} & \mathrm{cm} & \end{array}$

\begin{tabular}{|c|c|c|c|c|}
\hline $\mathrm{H}_{94-2}$ & $53.5-54.5$ & 1.0 & $18 / 7-1 / 8$ & \\
\hline $\mathrm{H}_{94-1}$ & $62.5-63.0$ & 0.5 & $13-20 / 6$ & Uncertain date \\
\hline $\mathrm{H}_{93-2}$ & $95.0-96.0$ & 1.0 & $11-16 / 9$ & \\
\hline $\mathrm{H}_{93-1}$ & $107.0-111.0$ & 4.0 & $\begin{array}{c}8-13 / 7 ; 17-23 / 7 \\
25-31 / 7\end{array}$ & $\begin{array}{l}\text { Very thick zone with } \\
\text { internal layering }\end{array}$ \\
\hline $\mathrm{H}_{92-3}$ & $156.5-161.5$ & $<1.0$ & $\begin{array}{c}28 / 7-2 / 8 ; 8-13 / 8 \\
20-25 / 8\end{array}$ & $\begin{array}{l}\text { Zone with multiple } \\
\text { layers, two distinct }\end{array}$ \\
\hline $\mathrm{H}_{92-2}$ & $164.0-165.0$ & 1.0 & $12-21 / 7$ & \\
\hline $\mathrm{H}_{92-1}$ & $168.0-169.0$ & 1.0 & $24 / 6-4 / 7$ & \\
\hline
\end{tabular}

* See Figure 2 for locations of the identified hoar layers in the pit stratigraphy.

${ }^{\dagger}$ Hoar-event timing based on field observations and interpretation of the $\mathrm{SSM} / \mathrm{I} 37 \mathrm{GHz}$ / $/ \mathrm{H}$ ratio data for the GISP2 site. 


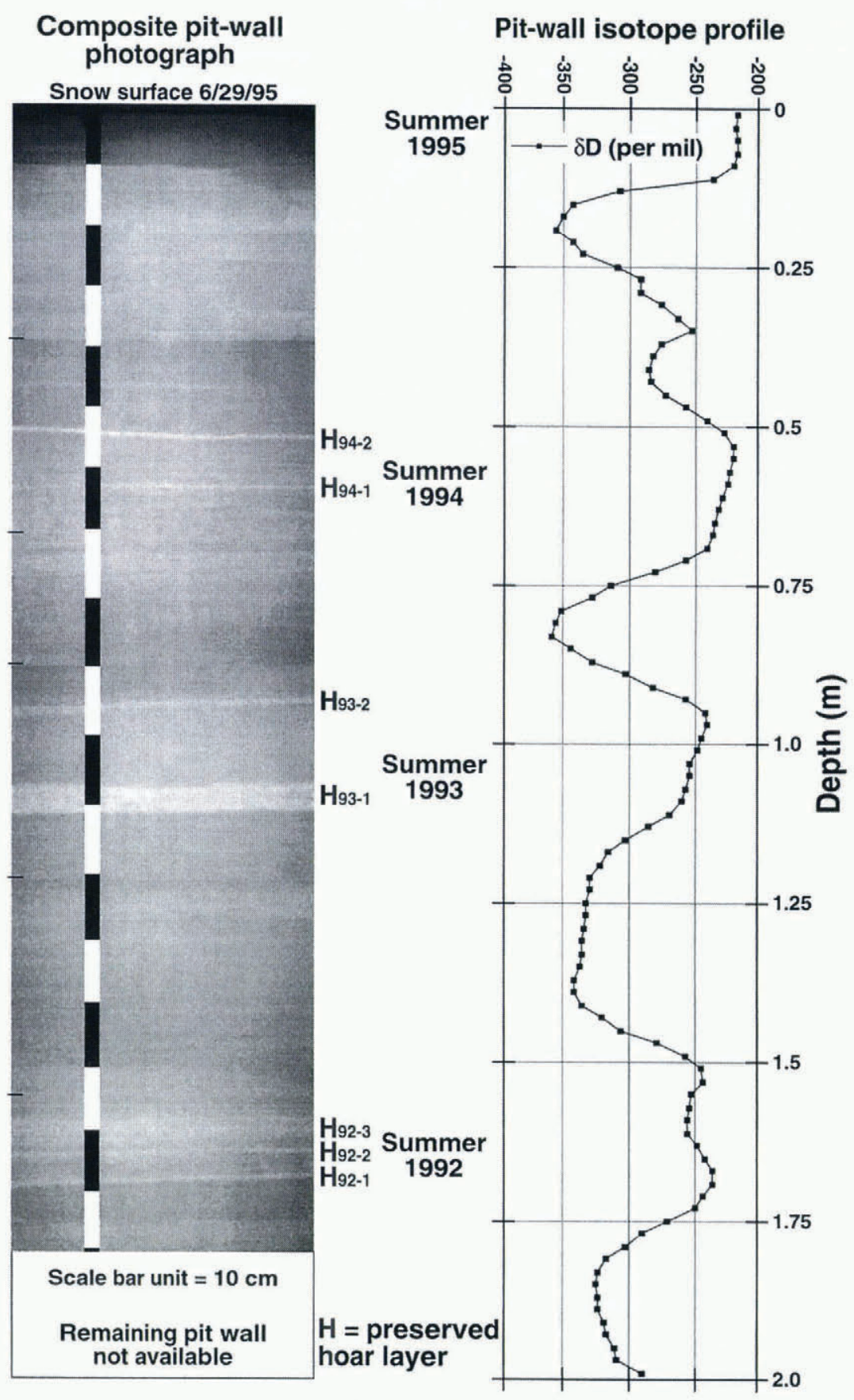

Fig. 1. Comparison of the composite photograph of the $2 \mathrm{~m}$ back-lit pit wall with the $2 \mathrm{~cm}$ sample-resolution profile of $\delta D(\%, m)$ (equivalent depth scale). Summer isotope peaks (smaller negative numbers) are indicated for each year between the two profiles. Hoar layers from the summers of 1992, 1993 and 1994 that were noted in the pit stratigraphy are marked with an H (see Table 1).

Note the dashes along the left side of the pit image that indicate the original photograph edges.

isotope trend as well as date and calibrated brightness temperature or $T_{\mathrm{C}}$ ) provide the basis for the following analyses. As in the previous work, to aid comparison with the $T_{\mathrm{B}}$ data, the isotope data are presented as if they represent a time series of $\delta$ values. Although diffusion is known to change isotopic values contained in snow and ice (Dansgaard and others, 1973; Johnsen, 1977; Whillans and Grootes, 1985; Friedman and others, 1991; Sommerfeld and others, 1991), no attempt has been made to correct the isotope values for its effects in this paper.

\section{RESULTS}

The daily average $37 \mathrm{GHz} \mathrm{V}$ brightness-temperature trend was directly compared to the isotope record from the approximate corresponding depth interval of the 1995 pit (see Fig. 2). This comparison documents that the multipeaked temperature cycle observed in the passive-microwave record is generally preserved in the snow-pit's isotope record. The 15 match points in this study were facilitated by detailed knowledge of when the hoar layers that are recorded in the pit stratigraphy were formed (see Fig. 1; Table 1). (Previous research has documented that hoar layers that form during the summer months and serve as the visible stratigraphy for dating ice cores can be distinguished and mapped with enhanced SSM/I data (Alley and others, 1993, 1997; Shuman and Alley, 1993; Shuman and others, 1993).) The seven hoar "zones" (see Table 1) identified in the pit stratigraphy correspond quite well with the isotopically heavier, less-negative $\delta$ values associated with summer accumulation. 


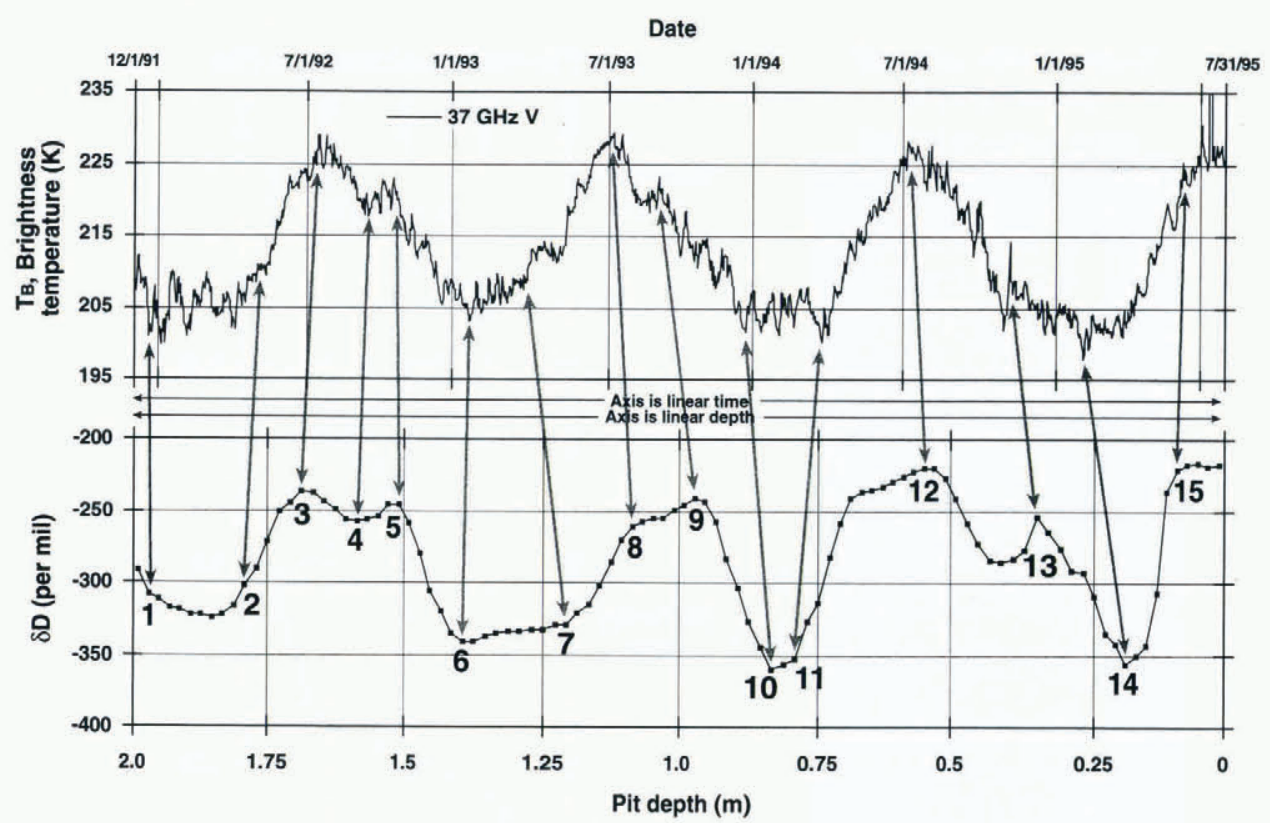

Fig. 2. Comparison of SSM/I-F11 $37 \mathrm{GHz}$ V brightness-temperature data ( $K$, daily average) with the stable-isotope record from the $2 \mathrm{~m}$ pit (\%o, $\mathrm{m}$ ). Match points are indicated by arrows and are numbered sequentially ( see Table 2). The comparison of these two trends, based on similarities in trend shape, was done at much higher resolution which allows dates to be assigned to pit depths (see Shuman and others, 1995b).

However, the isotopic profile appears to have been impacted by the formation of a very thick hoar layer, about $4 \mathrm{~cm}$, during the summer of 1993 (see Figs 2 and 3). This summer period lacks the characteristic isotopically heavier, less-negative, "warm" $\delta \mathrm{D}$ summer peak followed by a distinct secondary, late-fall or early-winter warm peak. The narrow depth range for this summer peak suggests that there was less accumulation overall through this time period, which is also suggested by observations during June reported by Bales and others (1995). Detailed analysis of the pit stratigraphy and the SSM/I V/H ratio covering this time period suggests that there was an anomalously long period of hoar formation that occurred in several stages (see Table 1) during most of July. What little snow did fall during July appears to have been incorporated into the large composite hoar layer (see Shuman and others, 1997, fig. 5). The process of hoar formation, according to Sommerfeld and others (1991), should cause depletion of lighter isotopes in mass-loss

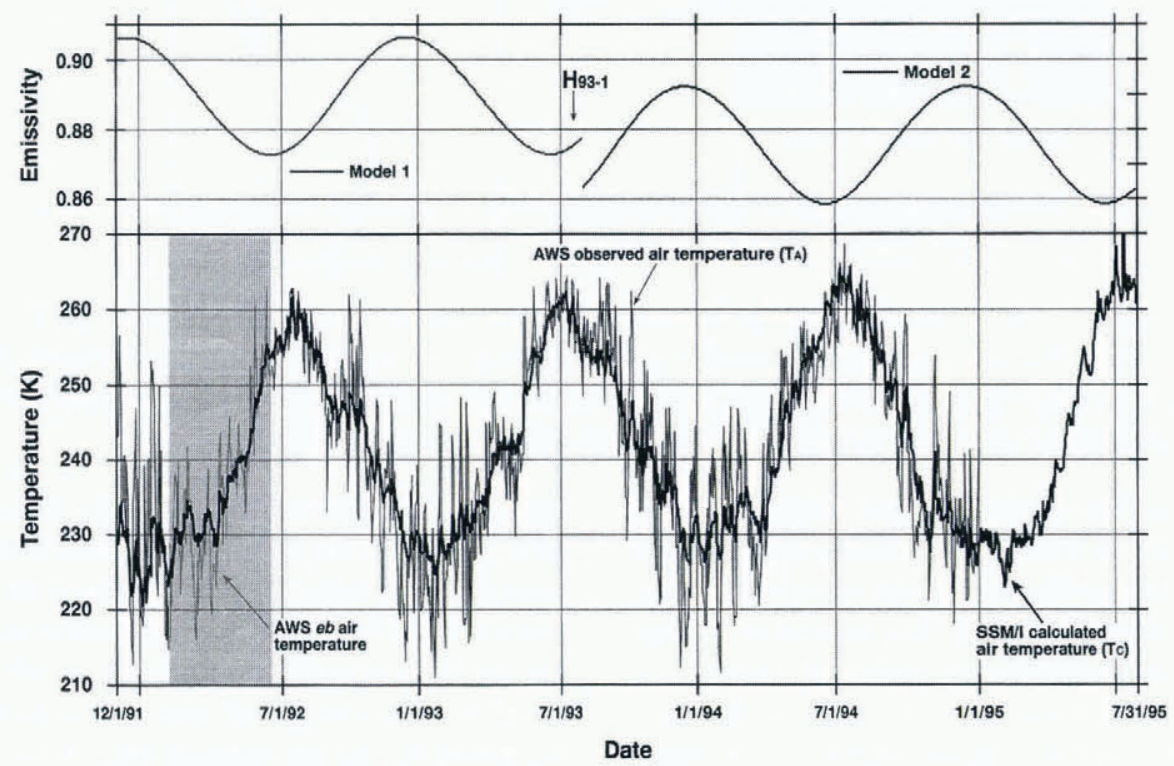

Fig. 3. Illustration of the relationship of the calculated air temperatures to the observed daily average AWS air-temperature record. The calculated air temperatures are derived from modeled emissivity cycles and SSM/I-F11 37 GHzV brightness-temperature data (see Shuman and others, 1995a) Two emissivity models were used to produce a satisfactory fit between the two temperature records. This result is probably due to the formation of the large hoar layer in fuly 1993 which indicates that $37 \mathrm{GHz}$ Vemissivity is not absolutely stable in this area over the long term. Note the close association of the calculated air-temperature trend to the observed air-temperature trend despite short-term, high-frequency air-temperature variations and data gaps in the AWS record. Equivalent-basis air-temperature data from AWS Kenton was inserted into the AWS GISP2 record to fill a large data gap extending from 8 February to 17 June 1992 for a total of 131 days (see Shuman and others, 1996). 
layers, indicating "warmer" conditions and enrichment of lighter isotopes in layers gaining mass, indicating "cooler" conditions. However, limited field data from the GISP2 site in July 1995 (unpublished data of C. A. Shuman) suggest that hoar development in this area is simply associated with enrichment of lighter isotopes at the surface, which results in the indicated "cooler" conditions. In any event, the combination of limited accumulation in June and development of a significant amount of surface hoar during July appears to have resulted in a relatively "cool" $\delta \mathrm{D}$ record through this time period. This result may also be partially explained if the last major accumulation events in this area occurred during the relatively colder May period.

The trend comparison of $T_{\mathrm{B}}$ and $\delta \mathrm{D}$ values for this pit indicates that the top $2 \mathrm{~m}$ of snow corresponds to more than three annual cycles. It also means that primary and secondary peaks and valleys can be compared reliably between the trends. This suggests that the stable-isotope records contained in the pits are derived from snow that has been accumulating at many times, and therefore at different temperatures, throughout the year. It should be noted that, although a distinct match-point date is determined for specific depths in the snow pit, there is a degree of uncertainty associated with these dates that is difficult to quantify.

\section{Water-equivalent isotope data}

The visual association of the $T_{\mathrm{B}}$ and $\delta \mathrm{D}$ records in Figure 2 provides the qualitative basis for this study. Quantitative information can be derived from correlations between the brightness-temperature records and density-corrected, water-equivalent depth profiles of isotope values. The 15 match points from the trend comparisons of this study are listed in Table 2 and were determined based on trend shapes, not magnitudes. Smoothed $T_{\mathrm{B}}$ profiles (15 day average) were

Table 2. Match-point data from trend comparisons

$\begin{array}{lccc}\begin{array}{c}\text { Match- } \\ \text { point }\end{array} & \text { Match-point } & \text { Sate } & \text { SSM/I } \\ \text { calculated } & & \delta D \text { per mil }\left(\delta^{18} O\right)^{\S} & \begin{array}{c}\text { Density- } \\ \text { corrected depth }\end{array} \\ \text { iden- } & & \text { temperature } & \\ \text { tifier } & & & \end{array}$

$\mathrm{m}$

\begin{tabular}{|c|c|c|c|c|}
\hline 23 Dec. 1991 & 222.22 & -308.50 & $(-39.81)$ & 0.685 \\
\hline 8 May 1992 & 240.70 & -302.28 & $(-39.04)$ & 0.617 \\
\hline 10 Jun. 1992 & 255.66 & -236.99 & $(-30.87)$ & 0.582 \\
\hline 14 Sep. 1992 & 244.81 & -257.24 & $(-33.410$ & 0.549 \\
\hline 14 Sep. 1992 & 244.81 & -257.24 & $(-33.41)$ & 0.54 \\
\hline 16 Oct. 1992 & 248.20 & -246.35 & $(-32.04)$ & 0.520 \\
\hline 20 Jan. 1993 & 224.70 & -341.29 & $(-43.91)$ & 0.477 \\
\hline 24 Mar. 1993 & 233.87 & -329.39 & $(-42.42)$ & 0.411 \\
\hline 29 Jun. 1993 & 261.18 & -261.25 & $(-33.91)$ & 0.369 \\
\hline 3 Sep. 1993 & 256.02 & -241.47 & $(-31.43)$ & 0.327 \\
\hline 20 Dec. 1993 & 226.39 & -360.02 & $(-46.25)$ & 0.277 \\
\hline 20 Mar. 1994 & 228.86 & -352.60 & $(-45.33)$ & 0.263 \\
\hline 6.Jul. 1994 & 265.48 & -219.49 & $(-28.69)$ & 0.184 \\
\hline 8 Nov. 1994 & 241.12 & -253.58 & $(-32.95)$ & 0.117 \\
\hline 28 Dec. 1994 & 225.79 & -356.86 & $(-45.86)$ & 0.062 \\
\hline 7Jun. 1995 & 262.42 & -220.65 & $(-28.83)$ & 0.032 \\
\hline
\end{tabular}

* See Figure 2 for locations of the match points.

${ }^{\dagger}$ Based on detailed examination of the SSM/I calculated temperature trend.

¥ See Figure 3 for the SSM/I calculated temperature trend.

$\S$ Deuterium data converted from $\delta \mathrm{D}$ to $\delta^{18} \mathrm{O}$ using the Craig (1961) equation. not used in this study (see Shuman and others, 1995b), because additional work indicated that smoothing the data did not significantly impact the precision of the match-point date. The water-equivalent depth profiles were generated from density-corrected isotope sample depths and these were used to determine accumulation amounts.

The match-point comparisons illustrated in Figure 2 reveal few anomalous isotopic values, identified by distinct differences in the brightness-temperature and isotope-trend patterns, except at match points 1 and 8 . Point 1 is the oldest match point and is likely to be the most influenced by diffusion of the isotopic signal. Also, the proximity of point 1 to the bottom of the pit allows the possibility that a better match point could have been found just below the bottom of the profile. Point 8 is probably anomalous due to its association with the extensive hoar event in July 1993 that is discussed above. Overall, it appears that the $T_{\mathrm{B}}$ and isotope trends tend to preserve a primary peak and trough as well as a secondary peak and trough per year, which can be used to identify four or more match points each year. More aggressive analysis and mathematical interpolation could conceivably produce other match-point pairs.

\section{Calibrated brightness temperatures}

Conversion of the SSM/I $T_{\mathrm{B}}$ data to calibrated near-surface air temperature $\left(T_{\mathrm{C}}\right)$ values is achieved through the use of an empirically derived emissivity function (see Fig. 3; Shuman and others, 1995a) which is based on the RayleighJeans approximation (Hall and Martinec, 1985). The Rayleigh-Jeans approximation describes the physical temperature of the near-surface snow as a function of the passivemicrowave brightness temperature divided by its emissivity. In this application of the approximation, it is assumed that the emissivity cycle is temporally stable. Figure 3 illustrates how well this approach can calibrate the SSM/I $37 \mathrm{GHz}$ V $T_{\mathrm{B}}$ data to the composite near-surface air-temperature $\left(T_{\mathrm{A}}\right)$ trend observed by the AWS at the GISP2 site (Stearns and Weidner, 1991). The AWS record is a composite due to the lack of $T_{\mathrm{A}}$ data from the GISP2 AWS from 8 February to 17 June 1992. Air-temperature data from AWS Kenton, the closest station to the GISP2 site, were integrated with the GISP2 $T_{\mathrm{A}}$ data using the "equivalent basis" technique (eb) described by Shuman and others (1996) (see Fig. 3).

From Figure 3, it can be seen that the assumption of temporal stability (Shuman and others, 1995a, b) of the modeled emissivity cycle is not valid. This is apparently due to the large composite hoar layer which formed in July 1993. Because of this, it was necessary to use two emissivity models, one before and one after the hoar event, in order to achieve a good fit of $T_{\mathrm{C}}$ to $T_{\mathrm{A}}$, although the fit using the second model is relatively poor for more than 1 month after the hoar formed. However, this does not affect the match-point data. The resulting offset or decrease in emissivity associated with this major hoar episode is consistent with the theoretical calculations by Fung and Chen (1981) which show that increasing surface roughness and decreased density, generally associated with hoar development (Shuman and Alley, 1993), result in a slight lowering of the $37 \mathrm{GHzV}$ $T_{\mathrm{B}}$ brightness temperature. Hoar development is also associated with larger snow grains and this is known to decrease emissivity (Zwally, 1977; Hall, 1987). Although the $T_{\mathrm{C}}$ trend, due to the $T_{\mathrm{B}}$ data, is clearly insensitive to short-term, highfrequency fluctuations in air temperature, the composite $T_{\mathrm{C}}$ 
record at the site describes the overall air-temperature trend quite accurately.

The reason for demonstrating the relationship of the $\delta \mathrm{D}$ values to the $\mathrm{SSM} / \mathrm{I}$-derived $T_{\mathrm{C}}$ values instead of directly to the observed air temperatures is simple. The number of AWS temperature sensors on the Greenland and Antarctic ice sheets is quite limited. However, the coverage of the $\mathrm{SSM} / \mathrm{I}$ sensor includes all of Greenland and all but $3^{\circ}$ at the South Pole (Hollinger and others, 1990; NSIDC, 1992). Therefore, snow-pit and shallow ice-core stable-isotope records can be usefully compared to brightness-temperature records even if they lack $T_{\mathrm{A}}$ records for calibration. As in the case for the Siple Dome drilling site in West Antarctica, AWS records will begin with the first field season (personal communication from C. Stearns). The short-term AWS temperature record should be able to calibrate, with some limitations, the much longer passive-microwave record for the site using the emissivity-modeling approach.

The match-point data from Table 2 and the resulting $T_{\mathrm{C}}$ vs $\delta^{18} \mathrm{O}$ plot (see Fig. 4) illustrate how reliably isotope values record (synthetic) near-surface air temperature. The slope of the regression line, $0.39 \pm 0.111$, is somewhat lower than the value $(0.46 \pm 0.075)$ reported by Shuman and others (1995b) but it is not significantly different given their error limits. (All \pm values reported here are for the $95 \%$ confidence limit. The $\delta \mathrm{D}$ values have been converted to a $\delta^{18} \mathrm{O}$ equivalent by the Craig (1961) equation $\left(\delta^{18} \mathrm{O}=(\delta \mathrm{D}-10) /\right.$ 8) to allow intercomparisons. Other sets of conversion coefficients, for example those based on Dye 3/4 data available in Johnsen and others (1989), could have been used. However, this has no significant effect on this analysis.)

The overall trend in the data is fairly well defined but there are several outliers. The match point 1 outlier is likely the product of diffusion as it is the "oldest" point in the analysis, although its proximity to the bottom of the pit allows the possibility of a better match point as mentioned above. The match point 8 outlier is apparently impacted by

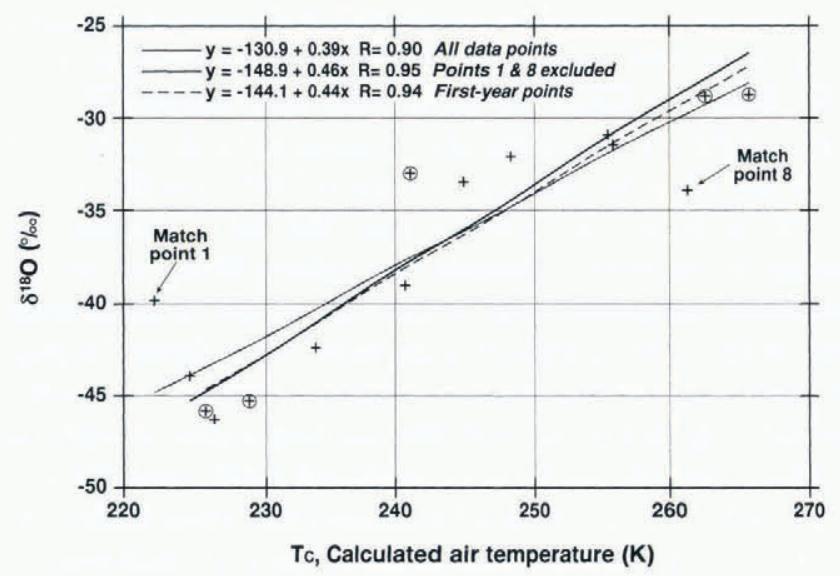

Fig. 4. Scatter plot of pairs of calculated air temperature, $T_{\mathrm{C}}$, and $\delta^{18} O$-equivalent values for the 15 match points ( see Table 2). The regression line defines the slope of the $T$ vs $\delta$ relationship, about 0.39, for this dataset. Removal of match point 1 (probably most affected by diffusion) and match point 8 (associated with a major hoar layer) increases the overall slope to 0.46. The slope of the regression line through only the first-year match points (five circles) has a slope of 0.44. All slope values presented here are within the $95 \%$ confidence intervals for the slope value (0.46) published by Shuman and others (1995b). the hoar-formation process (see Fig. 2). Removing both of them from the regression analysis produces a distinct increase in the $T$ vs $\delta$ slope value from 0.39 to 0.46 ( \pm 0.099 ) (see Fig. 4). The other outliers which occur mostly in the transitions from summer to winter appear isotopically "warm" which may be due to the contribution of water vapor from distant sources, complex isotope fractionation that is not simply temperature-driven (Charles and others, 1994; Newell and Zhu, 1994), or even drifting of geographically distant accumulation into the area. The generally reduced sensitivity of the $T_{\mathrm{C}}$ data, for the reasons discussed above, may also contribute to this problem. However, with match point 1 and 8 removed, the slope of the $T$ vs $\delta$ line is statistically consistent with the previous results using this technique (Shuman and others, 1995b), published estimates based on borehole paleothermometry (Cuffey and others, 1992, 1994) and modern spatial temperature isotope relationships (Dansgaard, 1964; Jouzel and others, 1997. As in Shuman and others (1995b), the slope of the "first-year" match points (those within approximately lyear of the pit sampling) alone was also examined. This reduced the slope values from 0.46 to 0.44 ( \pm 0.283 ) but, as it is based only on five data points, it is probably of limited significance.

\section{Accumulation amount, rate and timing estimates}

As mentioned above, the amount of accumulation can be calculated from the water-equivalent depth profile for each interval defined by the match-point data (see Fig. 5). This plot illustrates the amount of water-equivalent snow preserved in the profiles as a function of interval length. (These values reflect only the net amount over the interval, because these sub-annual time periods necessarily include periods with and without accumulation as well as possibly periods with loss of accumulation. For a general discussion of this problem, see Gardner and others, (1987).) The match-point dates from the $T_{\mathrm{B}}$ record therefore define the number of

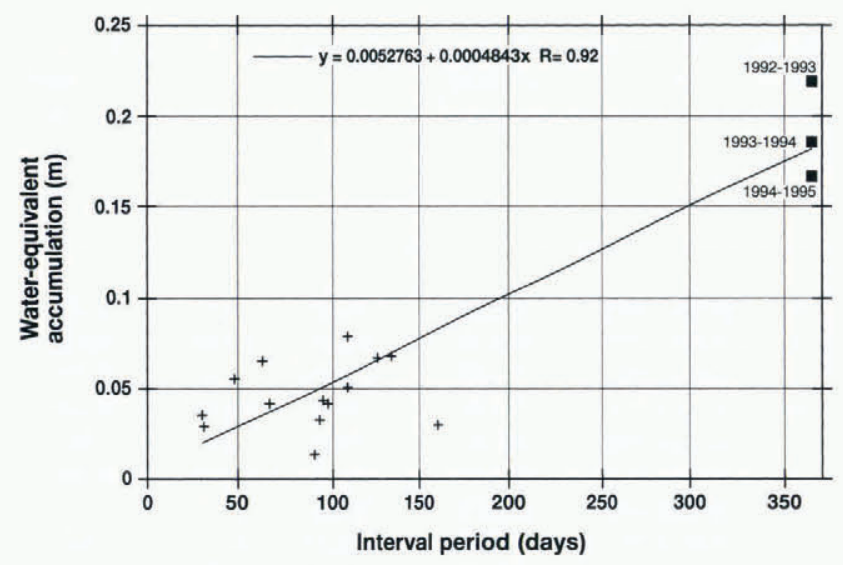

Fig. 5. Scatter plot of all accumulation amounts $(m)$ estimated for the 14 interval periods (pluses) between the match points identified in Table 2. Summer-to-summer annual accumulation values (squares) are estimated based on density-corrected data from Figure 2 and show a progressive decline from 0.22 to $0.17 \mathrm{~m}$ from 1992-93 to 1994-95. The regression line can be used to estimate the amount of accumulation that might be expected for an interval of a certain number of days through this time period around the GISP2 site, although this does not account for seasonal accumulation variations. 
days over which the corresponding amount of water-equivalent snow has accumulated. Annual accumulation amounts derived here show a progressive decline from the average modern accumulation rate of $0.24 \mathrm{~m} \mathrm{a}^{-1}$ (see Alley and others, 1993, fig. 1). This general decline is supported by unpublished data from the multi-year accumulation stake-line measurements conducted near the GISP2 site by researchers from the Cold Regions Research and Engineering Laboratory and The Pennsylvania State University from 1989 through 1995 (personal communication from D. Meese). It should be noted that these values are of the same magnitude as nearby accumulation rates $\left(0.28 \mathrm{~cm} \mathrm{a}^{-1}\right)$ found in the 1950s by Benson (1962). Preliminary analyses show no clear association of these accumulation data with the mean annual temperatures reported by Shuman and others (1996).

The same data can be used to measure the rate of accumulation (see Fig. 6). The range in accumulation rate is from about 0.47 to $3.50 \mathrm{~cm} \mathrm{month}^{-1}\left(0.15-1.15 \mathrm{~mm} \mathrm{~d}^{-1}\right)$ with a mean of about $1.89 \mathrm{~cm} \mathrm{month}^{-1}\left(0.62 \mathrm{~mm} \mathrm{~d}^{-1}\right)$ and all these values are lower than those in Shuman and others (1995b). As above, these rates are the net rate for the interval defined by pairs of the 15 match points. The highest value is for a relatively short interval (48 days), although slightly lower rates are observed for slightly shorter intervals of about 30 days. The mean interval is similar to that observed in the previous study at about 89 days.

In order to assess the timing of accumulation at the GISP2 site from these data, the observed accumulation-rate values were plotted relative to the interval midpoint date over an arbitrary year (see Fig. 6). As in Shuman and others (1995b; see Fig. 6), by fitting a simple annual sine wave, these data indicate the relative timing of accumulation throughout the "year" at the site. This analysis is consistent with our previous results and is generally supported by the accumulation-timing results of McConnell and others (1997, fig. 3 ), as well as the independent results of Bromwich and others

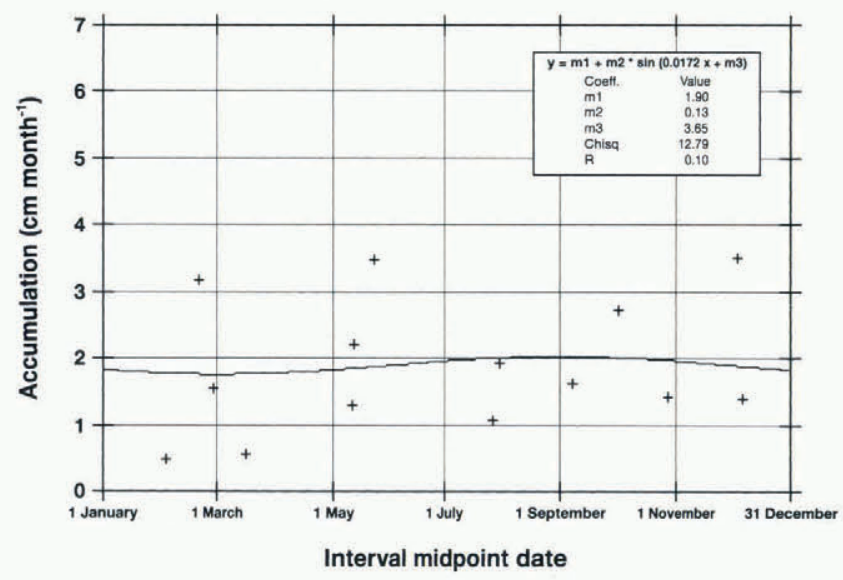

Fig. 6. Scatter plot of all the accumulation rate values $(\mathrm{cm} /$ month) plotted against the midpoint date of the interval ( scaled similar to that in Shuman and others, 1995b, fig. 6) over an arbitrary annual period. An annual-period sine-wave fit to this data indicates the relative timing of accumulation at the GISP2 site. Although the accumulation appears to reach a maximum in late summer into early fall, the scatter in the data indicates that there is a great deal of variability in the individual accumulation-rate values. The reduced amplitude, relative to Shuman and others (1995b, fig. 6), may be the result of declining accumulation during this period ( see Fig. 5).
(1993). Bromwich and others' atmospheric modeling results show that, for sites to the north and south of GISP2, more accumulation occurs across Greenland in the summer and fall than in winter and spring. Although the time interval studied here shows reduced accumulation overall and a damped seasonal cycle compared to the results of Shuman and others (1995b), this analysis shows accumulation occurring with a generally similar pattern. It is important to recognize that these results represent an assessment of temporally variable meteorological phenomena and caution should be used in interpretation of the absolute accumulation values.

\section{Peroxide deposition cycle}

To check the reliability of the trend-comparison technique, this study utilized data on a particular chemical species, peroxide $\left(\mathrm{H}_{2} \mathrm{O}_{2}\right)$, because of its known atmospheric cycle and strong seasonal dependence (Bales and Choi, 1996; McConnell and others, 1997). This aspect was also included in this study, because there is a great deal of interest by the paleoclimate community in the "transfer function" or the overall mechanism responsible for moving chemical constituents from the atmosphere into the ice sheet, which is partially controlled by the timing of accumulation (Bergin and others, 1994; McConnell and others, 1996, 1997). As a result, a University of Arizona field team took a parallel $2 \mathrm{~cm}$ resolution $\mathrm{H}_{2} \mathrm{O}_{2}$ profile in a snow pit immediately adjacent to the one used for the isotope data. These samples were analyzed in the field using a peroxidase technique described by Sigg and others (1992) and Bales and others (1995) with an accuracy of $\pm 5 \%$. The resulting profile is shown in Figure $7 \mathrm{a}$ along with the times associated with the 15 correlations from the match-point data. As with the $\delta \mathrm{D}$ data, the $\mathrm{H}_{2} \mathrm{O}_{2}$ data are presented in Figure $7 \mathrm{a}$ as if they represent a time series, despite variability in accumulation rate and postdepositional effects.

The relationship between atmospheric $\mathrm{H}_{2} \mathrm{O}_{2}$ concentration, the result of a complex set of reactions as described in Sigg and others (1992), and the amount preserved in the snowpack is thought to be a highly non-linear function of temperature and accumulation rate (McConnell and others, 1996). The variability of the multi-year signal from this dataset indicates that summer $\mathrm{H}_{2} \mathrm{O}_{2}$ deposition is relatively high and that winter $\mathrm{H}_{2} \mathrm{O}_{2}$ deposition is low, although there is considerable variability in the magnitude of the summer maxima (see Fig. 7a). The lower accumulation observed during the summer of 1993 or the hoar-formation process mentioned above may be responsible for the reduced magnitude of the $\mathrm{H}_{2} \mathrm{O}_{2}$ peak through this part of the record.

The snow-pit data can be compared with the theoretical atmospheric concentration of $\mathrm{H}_{2} \mathrm{O}_{2}$ through this time period (see Figure 7b) via a photochemical model of atmospheric $\mathrm{H}_{2} \mathrm{O}_{2}$ concentration (Bales and Choi, 1996; McConnell and others, 1997) and the following technique. By first scaling the observed $\mathrm{H}_{2} \mathrm{O}_{2}$ values from the snow-pit profile for each year between 0 and 1 to minimize the year-to-year variability in the data and then linearly interpolating between match-point dates to determine the approximate deposition date of all samples, a dataset was created that approximates the multi-year deposition timing of $\mathrm{H}_{2} \mathrm{O}_{2}$. Although there is a good deal of noise in the resulting "observed (scaled)" snow-pit data (see Fig. 7b), it appears 

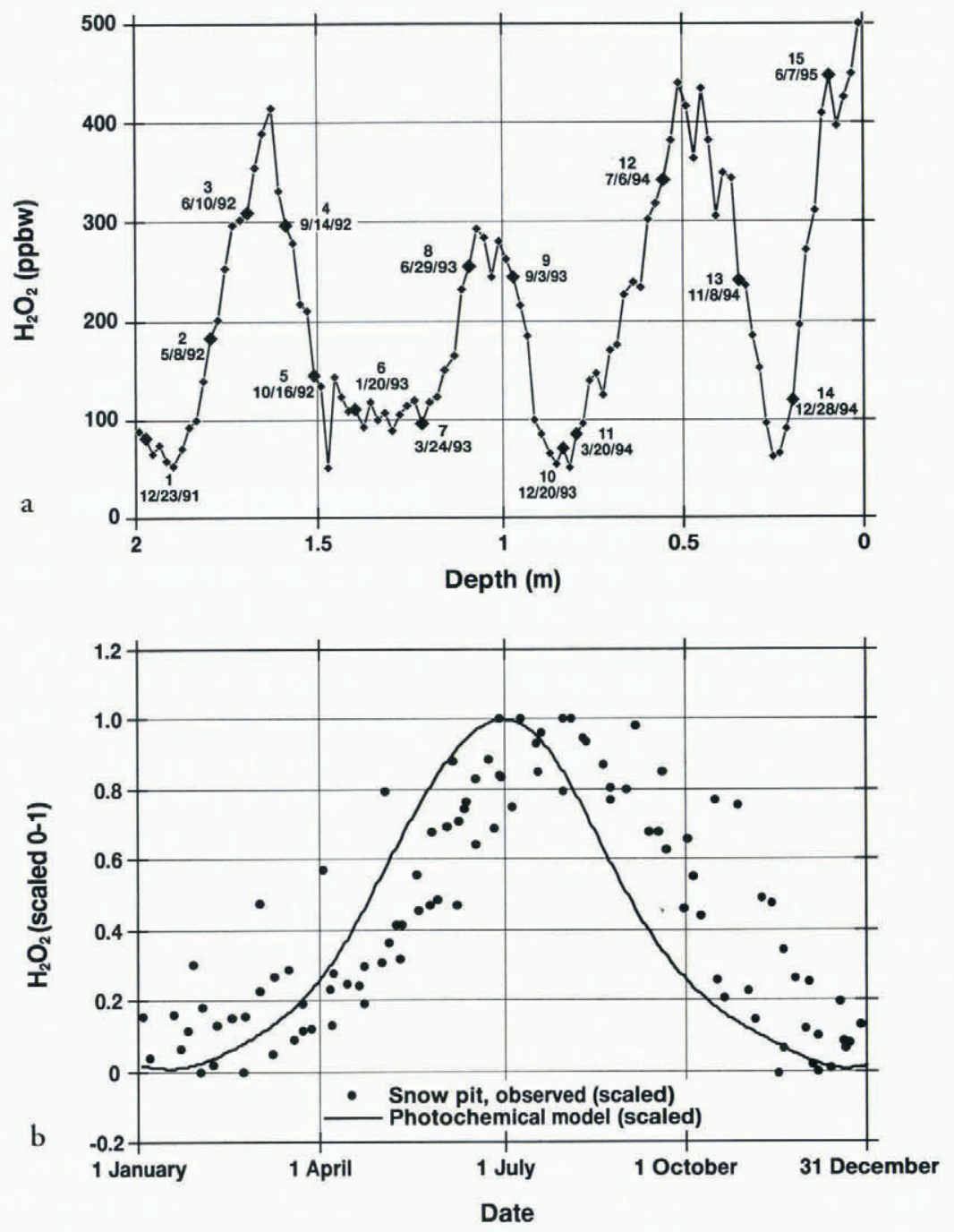

Fig. 7. Application of the match-point technique to the interpretation of an adjacent chemistry profile: (a) illustration of the $\mathrm{H}_{2} \mathrm{O}_{2}$ profile from the 1995 pit with dates assigned to profile depths based on the 15 match-point comparisons in Figure 2; and (b) the resulting temporally constrained $\mathrm{H}_{2} \mathrm{O}_{2}$ values plotted relative to an arbitrary year and to the atmospheric $\mathrm{H}_{2} \mathrm{O}_{2}$ photochemical model from McConnell and others (1996). The offset illustrates the lag in the timing of $\mathrm{H}_{2} \mathrm{O}_{2}$ deposition at the GISP2 site.

to be similar in magnitude to the variability in the observed atmospheric values from the GISP2 site (McConnell and others, in press, fig. 3). By similarly scaling the photochemical model between 0 and 1 , a direct comparison can be made between the theoretical atmospheric and observed snowperoxide concentrations. The overall similarity between these scaled datasets suggests the following conclusion: the offset between the photochemical model of atmospheric concentration and the "observed (scaled)" profile values is consistent with the known lag between $\mathrm{H}_{2} \mathrm{O}_{2}$ production (July) and preservation (August) in the ice sheet (Bales and Choi, 1996; McConnell and others, 1997). The photochemical model leads the observed deposition in the spring and then lags it more significantly in the fall. This increased lag in the fall is consistent with the cycle of accumulation derived earlier (Fig. 6) and suggests delivery of $\mathrm{H}_{2} \mathrm{O}_{2}$ from southerly latitudes as photochemical production ceases over central Greenland during the onset of the polar winter. Together, these results suggest that the match-point dates are reasonable estimates of accumulation timing and that the technique is reliable. This test is still tentative as the use of scaled data from multiple years of accumulation to compare with the current $\mathrm{H}_{2} \mathrm{O}_{2}$ photochemical model is not precise. However, if this approach is correct, the matchpoint technique can be used reliably for other chemical compounds and may prove valuable to investigations of the atmospheric-transfer function.

\section{DISCUSSION}

The research presented here is entirely consistent with the previous effort (Shuman and others, 1995b) and confirms: (1) that there is a high degree of similarity between $T_{\mathrm{A}}$ and $T_{\mathrm{B}}$ records from the Summit region of central Greenland; (2) both the $\delta \mathrm{D}$ profile and the $T_{\mathrm{B}}$-derived trend have temporally equivalent primary and secondary features that correspond over a number of years and, therefore; (3) these latter two records preserve in detail the known annual and sub-annual variations in temperature for this site. This is assisted by identification of temporally constrained hoar layers in the snow-pit stratigraphy. As a result, it appears that in this region $\delta \mathrm{D}$ is a reliable temperature indicator and that it is preserved in a series of accumulation events that occur frequently throughout the year. As such, these results validate, at least for multi-year periods, the use of the stable isotopes of hydrogen and oxygen as indicators of paleotemperature.

However, it should be noted that quantitative analysis of the data produced using the point-matching technique 
depends on a number of assumptions. First, this approach assumes that all the significant maxima and minima identified in the isotope record are associated temporally with meteorological phenomena that impact the brightnesstemperature record. This assumption is unlikely to be absolutely true and necessarily controls to some extent the selection of match points (i.e. not all "events" in the brightnesstemperature record have an associated isotope feature; snow from an event must be preserved to provide a match point). However, it is highly probable that the significant peaks and valleys observed in the AWS and $T_{\mathrm{B}}$ records have accumulation associated with them, possibly within a few days (Steffensen, 1985). Secondly, even using high-resolution sampling with $2 \mathrm{~cm}$ increments, it is likely that there is some smoothing of isotope values through time and therefore the isotope record presented here imperfectly represents the actual signal contained in the original accumulating snow. This is partially related to depositional processes which in this area act to "homogenize" the near-surface snow through the micro-scale redistribution of snow grains and water vapor, as well the impact of the sampling "increment". Thirdly, isotope diffusion may cause peak-and-valley migration through time and generally smooth the isotope record to the point that critical detail is lost. However, this does not appear to be the case here, except possibly for the first and oldest match point as discussed previously (also, see "analysis and discussion on diffusion" in Shuman and others, 1995b). Fourthly, as detailed density profiles are likely to have some error, the water-equivalent accumulation values are likely to be imperfect. This may contribute to some variability in this part of the analysis. As a result of these problems, it is possible that the results determined by the match-point technique are slightly in error and therefore the timing data should be considered as estimates with a degree of uncertainty associated with them. Although each concern may be true for any single point in the analysis, it is unlikely that these problems cause a systematic bias to the data and therefore the overall analysis and its results are still valid. And, finally, the preliminary investigations into the deposition of $\mathrm{H}_{2} \mathrm{O}_{2}$ need to be repeated using additional data and possibly other chemical parameters. In their analysis of $\mathrm{H}_{2} \mathrm{O}_{2}$ transfer from the atmosphere to the snowpack, McConnell and others (1997) have suggested that the association of stable isotopes in accumulating snow to temperature is more complex than is assumed here. However, there are some uncertainties in their analysis approach regarding the timing of accumulation which make it difficult to address this issue. In any event, the results presented here are internally consistent and suggest that the match-point method is a reliable means of assigning a time to a specific depth in the snowpack in central Greenland.

\section{CONCLUSIONS}

We have confirmed a recognized correspondence between a $\delta \mathrm{D}$ profile from a shallow snow pit and daily average brightness-temperature records (SSM/I-F1l $37 \mathrm{GHzV}$ channel) from the GISP2 site. A distinctive, multi-peaked temperature cycle can be observed with AWS and long-term satellite-temperature data, and it appears to be substantially preserved in the snow-pit stable-isotope record. The similarity between the trends, despite a major hoar event and prob- able diffusion, supports the conclusion that accumulation in this area occurs at many times throughout the year and that isotopic data from the GISP2 site initially preserve a temperature profile with sub-seasonal resolution. Application of this new technique at other sites on the great polar ice sheets may allow the distribution and timing of accumulation to be estimated as well as assessment of the general reliability of isotope thermometry over multi-year periods. This technique may also contribute to the difficult issue of defining the atmospheric transfer function for specific chemical parameters.

\section{ACKNOWLEDGEMENTS}

We thank the Science Management Office, Polar Ice Coring Office, and 109th Air National Guard for logistical support, as well as D. Meese, C. Jung, II, G. Landis, M. Sturm, two helpful reviewers, and other GISP2 colleagues for their technical support. This research was supported by the U.S. National Science Foundation and NASA. This work was begun while the first author held a U.S. National Research Council Associateship at NASA/Goddard Space Flight Center, and concluded during an appointment with the Universities Space Research Association at NASA/Goddard Space Flight Center (Contract No. NAS5-32484).

\section{REFERENCES}

Alley, R. B., E. S. Saltzman, K. M. Cuffey and J. J. Fitzpatrick. 1990. Summertime formation of depth hoar in central Greenland. Geophys. Res. Lett., 17 (12), 2393-2396.

Alley, R. B. and 10 others. 1993. Abrupt increase in Greenland snow accumulation at the end of the Younger Dryas event. Nature, 362 (6420), 527-529.

Alley, R. B. and 11 others. 1997. Visual-stratigraphic dating of the GISP2 ice core: basis, reproducibility, and application. 7. Geophys. Res., 102(C12), $26,367-26,382$

Armstrong, R. L., A. Chang, A. Rango and E. Josberger. 1993. Snow depths and grain-size relationships with relevance for passive microwave studies. Ann. Glaciol., 17, 171-176.

Bales, R. C. and J. Choi. 1996. Conceptual framework for interpretation of exchange processes. In Wolff, E. W. and R. C. Bales, eds. Chemical exchange between the atmosphere and polar snow. Berlin, etc., Springer-Verlag, 319-338. (NATO ASI Series I: Global Environmental Change 43.

Bales, R. C. and 8 others. 1995. The diel variations of $\mathrm{H}_{2} \mathrm{O}_{2}$ in Greenland: a discussion of the cause and effect relationship. 7. Geophys. Res., 100 (D9), $18,66 \mathrm{l}-18,668$

Barlow, L. K., J.W. C. White, R. G. Barry, J. C. Rogers and P. Grootes. 1993. The North Atlantic oscillation signature in deuterium and deuterium excess signals in the Greenland Ice Sheet Project 2 ice core, 1840-1970. Geophys. Res. Lett., 20 (24), 2901-2904.

Benson, C. S. 1962. Stratigraphic studies in the snow and firn of the Greenland ice sheet. SIPRE Res. Rep. 70.

Bergin, M. H., J. -L. Jaffrezo, C. I. Davidson, R. Caldow and J. Dibb. 1994. Fluxes of chemical species to the Greenland ice sheet at Summit by fog and dry deposition. Geochim. Cosmochim. Acta, 58(15), 3207-3215.

Bromwich, D. H., F. M. Robasky, R. A. Keen and J. F. Bolzan. 1993. Modeled variations of precipitation over the Greenland ice sheet. f. Climate, 6(7), 1253-1268.

Chang, A. T. C., P. Gloersen, T. Schmugge, T.T. Wilheit and H. J. Zwally. 1976. Microwave emission from snow and glacier ice. .7. Glaciol., 16 (74), $23-39$.

Charles, C. D., R. Rind, J. Jouzel, R. D. Koester and R. G. Fairbanks. 1994. Glacial-interglacial changes in moisture sources for Greenland: influences on the ice core record of climate. Science, 263(5146), 508-511.

Craig, H. 1961. Isotopic variations in meteoric waters. Science, 133(3465), 1702-1703.

Cuffey, K. M. and G. Clow. 1997. Temperature, accumulation, and ice sheet elevation in central Greenland through the last deglacial transition. $\mathcal{F}$. Geophys. Res., 102 (Cl2), 26,383-26,398.

Cuffey, K. M., R. B. Alley, P. M. Grootes and S. Anandakrishnan. 1992. Toward using borehole temperatures to calibrate an isotopic paleothermometer in central Greenland. Global and Planetary Change, 6(2-4), 
265-268.

Cuffey, K. M., R. B. Alley, P. M. Grootes, J. M. Bolzan and S. Anandakrishnan. 1994. Calibration of the $\delta^{18} \mathrm{O}$ isotopic paleothermometer for central Greenland, using borehole temperatures. F. Glaciol., 40 (135), 341-349.

Dansgaard, W. 1964. Stable isotopes in precipitation. Tellus, 16 (4), 436-468.

Dansgaard, W., S. J. Johnsen, H. B. Clausen and N. Gundestrup. 1973. Stable isotope glaciology. Medd. Grenl., 197(2), 1-53.

Dansgaard, W., H. B. Clausen, N. Gundestrup, S. J. Johnsen and C. Rygner. 1985. Dating and climatic interpretation of two deep Greenland ice cores. In Langway, C.C., Jr, H. Oeschger and W. Dansgaard, eds. Greenland ice core: geophysics, geochemistry, and the environment. Washington, DC, American Geophysical Union, 71-76. (Geophysical Monograph 33.)

Epstein, S., R. P. Sharp and A. J. Gow. 1965. Six-year record of oxygen and hydrogen isotope variations in South Pole firn. 7. Geophys. Res., 70(8), 1809-1814.

Fisher, D. A., R. M. Koerner, W. S. B. Paterson, W. Dansgaard, N. Gundestrup and N. Reeh. 1983. Effect of wind scouring on climatic records from icecore oxygen-isotope profiles. Nature, 301 (5897), 205-209.

Friedman, I., C. Benson andJ. Gleason. 1991. Isotopic changes during snow metamorphism. In Taylor, H. P., Jr, J. R. O'Neill and I. R. Kaplan, eds. Stable isotope geochemistry: a tribute to Samuel Epstein. Washington, DC, Geochemical Society, 211-221. (Special Publication 3.)

Fung, A. K. and M. F. Chen. 1981. Emission from an inhomogeneous layer with irregular interfaces. Radio Sci., 16 (3), 289-298.

Gardner, T.W., D. W. Jorgensen, C. A. Shuman and C. Lemieux. 1987, Geomorphic and tectonic process rates: effects of measured time interval. Geology, 15, 259-261.

Grootes, P. M. and M. Stuiver. $1997 .{ }^{18} \mathrm{O} /{ }^{16} \mathrm{O}$ variability in Greenland snow and ice with $10^{-3}$ to $10^{5}$ year time resolution. 7. Geophys. Res, $102(\mathrm{Cl} 2)$, $26,455-26,470$.

Grootes, P. M., M. Stuiver, J.W. C. White, S. Johnsen and J. Jouzel. 1993. Comparison of oxygen isotope records from the GISP2 and GRIP Greenland ice cores. Nature, $\mathbf{3 6 6}(6455), 552-554$

Hall, D. K. 1987. Influence of depth hoar on microwave emission from snow in northern Alaska. Cold Reg. Sci. Technol., 13(3), 225-231.

Hall, D. K. and J. Martinec. 1985. Remote sensing of ice and snow. London and New York, Chapman and Hall Ltd.

Hammer, C. U., H. B. Clausen, W. Dansgaard, N. Gundestrup, S. J. Johnsen and N. Reeh. 1978. Dating of Greenland ice cores by flow models, isotopes, volcanic debris, and continental dust. 7. Glaciol., 20 (82), 3-26.

Hollinger, J. P., J. E. Pierce and G. A. Poe. 1990. SSM/I instrument evaluation. IEEE Trans. Geosci. Remote Sensing, GE-28 (5), 781-790.

Johnsen, S. J. 1977. Stable isotope homogenization of polar firn and ice. International Association of Hydrological Sciences Publication 118 (Symposium at Grenoble 1975 - Isotopes and Impurities in Snow and Ice ), 210-219.

Johnsen, S. J., W. Dansgaard and J.W. C. White. 1989. The origin of Arctic precipitation under present and glacial conditions. Tellus, 41B (4), 452-468.

Jouzel, J. and L. Merlivat. 1984. Deuterium and oxygen 18 in precipitation: modeling of the isotopic effect during snow formation. 7. Geophys. Res., 89 (D 7), 11,749-11,757.

Jouzel, J. and 12 others. 1997. On the validity of the temperature reconstruction from water isotopes in ice cores. F. Geophys. Res., 102 (Cl2), 26,47126,488 .

Kato, K. 1978. Factors controlling oxygen isotopic composition of fallen snow in Antarctica. Nature, 272 (5648), 46-48.

Maslanik, J. A., J. R. Key and R. G. Barry. 1989. Merging AVHRR and SMMR data for remote sensing of ice and cloud in polar regions. Int. $y$. Remote Sensing, 10 10$), 1691-1696$.

McConnell, J. R., A. M. Thompson and R. C. Bales. 1996. Surface snow as a proxy for atmospheric hydrogen peroxide at South Pole. EOS, 77(17), Spring Meeting Supplement, S156.

McConnell, J. R., R. C. Bales, J. R. Winterle, H. Kuhns and C. R. Stearns.
1997. A lumped parameter model for the atmosphere-to-snow transfer function for hydrogen peroxide. f. Geophys. Res., 102 (Cl2), 26,809-26,818.

National Snow and Ice Data Center (NSIDC). 1992. DMSP SSM/I brightness temperature and sea ice concentration grids for the polar regions on CD-ROM. Users'guide. Boulder, CO, National Snow and Ice Data Center. (Special Report l.)

Newell, R. E. and Y. Zhu. 1994. Tropospheric rivers: a one-year record and a possible application to ice core data. Geophys. Res. Lett., 21 (2), 113-116.

Peel, D. A., R. Mulvaney and B. M. Davison. 1988. Stable-isotope/airtemperature relationships in ice cores from Dolleman Island and the Palmer Land Plateau, Antarctic Peninsula. Ann. Glaciol., 10, 130-136.

Petit, J. R., J.W. C. White, N.W. Young, J. Jouzel and Ye. S. Korotkevich. 1991. Deuterium excess in recent Antarctic snow. 7. Geophys. Res., 96(D3), 5113-5122.

Rott, H., K. Sturm and H. Miller. 1993. Active and passive microwave signatures of Antarctic firn by means of field measurements and satellite data. Ann. Glaciol., 17, 337-343.

Shuman, C. A. and R. B. Alley. 1993. Spatial and temporal characterization of hoar formation in central Greenland using SSM/I brightness temperatures. Geophys. Res. Lett., 20(23), 2643-2646.

Shuman, C. A., R. B. Alley and S. Anandakrishnan. 1993. Characterization of a hoar-development episode using SSM/I brightness temperatures in the vicinity of the GISP2 site, Greenland. Ann. Glaciol., 17, 183-188.

Shuman, C. A., R. B. Alley, S. Anandakrishnan and C. R. Stearns. 1995a. An empirical technique for estimating near-surface air temperature trends in central Greenland from SSM/I brightness temperatures. Remote Sensing Environ., 51 (2), 245-252.

Shuman, C.A., R. B. Alley, S. Anandakrishnan, J.W. C. White, P. M. Grootes and C. R. Stearns. 1995b. Temperature and accumulation at the Greenland Summit: comparison of high-resolution isotope profiles and satellite passive microwave brightness temperature trends. J. Geophys. Res., 100 (D5), 9165-9177.

Shuman, C. A., M. A. Fahnestock, R. A. Bindschadler, R. B. Alley and C. R. Stearns. 1996. Composite temperature record from the Greenland Summit, 1987-1994: synthesis of multiple automatic weather station records and SSM/I brightness temperatures. F. Climate, $9(6), 1421-1428$.

Shuman, C. A. and 6 others. 1997. Detection and monitoring of annual indicators and temperature trends at GISP2 using passive microwave remote sensing data. F. Geophys. Res., 102 (C12), 26,877-26,886.

Sigg, A., T. Staffelbach and A. Neftel. 1992. Gas phase measurements of hydrogen peroxide in Greenland and their meaning for the interpretation of $\mathrm{H}_{2} \mathrm{O}_{2}$ records in ice cores. 7. Almos. Chem., 14 (1-4), 223-232.

Sommerfeld, R. A., C. Judy and I. Friedman. 1991. Isotopic changes during the formation of depth hoar in experimental snowpacks. In Taylor, H. P., Jr, J. R. O'Neill and I. R. Kaplan, eds. Stable isotope geachemistry: a tribute to Samuel Epstein. Washington, DC, Geochemical Society, 205-209. (Special Publication 3.)

Sorge, E. 1935. Glaziologische Untersuchungen in Eismitte. In Brockamp, B. and others, eds. Glaziologie. Vol. 3. Leipzig, F.A. Brockhaus, 62-270.

Stearns, C. R. and G. A. Weidner. 1991. Snow temperature profiles and heat fluxes measured on the Greenland crest by automatic weather stations. In Weller, G., C. L. Wilson and B. A. B. Severin, eds. International Conference on the Role of the Polar Regions in Global Change: proceedings of a conference held fune 11-15, 1990 at the University of Alaska Fairbanks. Vol. I. Fairbanks, AK, University of Alaska. Geophysical Institute/Center for Global Change and Arctic System Research, 223-226.

Steffensen, J. P. 1985. Microparticles in snow from the South Greenland ice sheet. Tellus, 37B, 286- 295.

Whillans, I. M. and P. M. Grootes. 1985. Isotopic diffusion in cold snow and firn. 7. Geophys. Res., 90 (D2), 3910-3918.

Zwally, H.J. 1977. Microwave emissivity and accumulation rate of polar firn. f. Glaciol., 18(79), 195-215. 